\title{
Intermediate Risk Acute Myeloid Leukemia
}

National Cancer Institute

\section{Source}

National Cancer Institute. Intermediate Risk Acute Myeloid Leukemia. NCI Thesaurus.

Code C162456.

Acute myeloid leukemia with a risk of relapse or refractoriness between favorable and high risk acute myeloid leukemia, and cytogenetic and molecular genetic abnormalities that categorize it as intermediate risk acute myeloid leukemia. 